\title{
Complication versus Radicality in Papillary Thyroid Cancer Surgery: How to Keep the Balance?
}

\author{
Ali Zedan1, Badawy M. Ahmed', Mohamed Ismail Omar'1, Waleed Ahmed Diab', \\ Hemat A. Mahmoud ${ }^{2}$, Haisam Atta $^{3}$ \\ ${ }^{1}$ Surgical Oncology Department, South Egypt Cancer Institute, Assuit University, Assiut, Egypt \\ ${ }^{2}$ Nuclear Medicine Department, South Egypt Cancer Institute, Assuit University, Assiut, Egypt \\ ${ }^{3}$ Diagnostic Radiology Department, South Egypt Cancer Institute, Assuit University, Assiut, Egypt \\ Email: alizedan73@yahoo.com
}

How to cite this paper: Zedan, A., Ahmed, B.M., Omar, M.I., Diab, W.A., Mahmoud, H.A. and Atta, H. (2019) Paper Title. Journal of Cancer Therapy, 10, 1013-1024. https://doi.org/10.4236/jct.2019.1012085

Received: January 5, 2019

Accepted: January 31, 2019

Published: Deccember 27, 2019

Copyright $\odot 2019$ by author(s) and Scientific Research Publishing Inc. This work is licensed under the Creative Commons Attribution International License (CC BY 4.0).

http://creativecommons.org/licenses/by/4.0/ (c) (i) Open Access

\begin{abstract}
Background: Controversy exists over the extent of surgical treatment of papillary thyroid cancer. Reoperations may carry a significant risk of surgical complications. The aim of this study is to investigate the complications following surgical treatment of thyroid cancer and the association between the extent of surgery and complication rates. Methods: A total of 196 patients with papillary thyroid cancer were retrospectively reviewed to identify extent of surgery and associated complications, between 2009 and 2018 at South Egypt Cancer Institute Assiut University. Results: Primary procedures included less-than-total thyroidectomy (near total thyroidectomy in $5.1 \%$, subtotal thyroidectomy in $4.1 \%$, thyroid lobectomy in $3.1 \%$ ) and total thyroidectomy in $87.8 \%$ ( $18.9 \%$ of them are completion thyroidectomy). No lymph nodes dissection was done in $10.7 \%$, Berry picking in $6.1 \%$, central compartment neck dissection in $41.8 \%$, central compartment neck dissection with modified ipsilateral radical neck dissection in $12.2 \%$, central compartment neck dissection with modified bilateral radical neck dissection in $26.0 \%$, central compartment dissection with both modified bilateral radical neck dissection and superior mediastinal lymph node dissection $3.1 \%$. The most common surgical complication were transient hypoparathyroidism $(16.7 \%-45.8 \%)$ and $2.0 \%$ permanent, transient vocal cord palsy $(7.3 \%-16.7 \%)$, and $3.9 \%$ permanent, hematoma $1.5 \%$, seroma $7.1 \%$ and chyle fistula in $2.6 \%$ of patients. Conclusion: Thyroid cancer surgeries are safe. The transient complication rates of hypoparathyroidism increased significantly with increasing the extent of surgery.
\end{abstract}

\section{Keywords}

Complications, Thyroid Cancer, Thyroidectomy, Lymph Node Dissection 


\section{Introduction}

Papillary thyroid carcinoma (PTC) accounts for $>80 \%$ of all thyroid malignancies and is the most indolent form of the disease [1]. The overall prognosis is excellent, with 5-year, 10 -year, and 20 -year survival rates of $94 \%, 89 \%$, and $87 \%$, respectively. Cervical lymph node metastasis occurs frequently in PTC (10\% to $15 \%)$ with more aggressive biology and requires treatment with more aggressive regimens [2]. Optimal extent of thyroid resection and lymph node dissection (LND) remain controversial [3]. Based on the extent of disease, total thyroidectomy or less-than-total thyroidectomy is chosen. Central compartment LND is usually performed with thyroidectomy on prophylactic base, whereas lateral LND is performed only in patients with clinically evident nodal metastasis.

Extended resection is reported to improve survival rate and decrease recurrence rate however, significantly increased complication rates [4]. The complications of thyroid surgery correlate proportionally to the extent of thyroidectomy and inversely to the surgeon experience. Some of the complications may result in worse outcome than the disease itself such as recurrent laryngeal nerve injury, or permanent hypoparathyroidism [5]. We, therefore, investigated surgical complications after thyroid cancer surgery and the association between the extent of surgery and complication rates.

\section{Patients and Methods}

We conducted a retrospective analysis. The medical records of 196 with PTC patients in south Egypt cancer institute, Assiut University, 10 years between January 1, 2009 and December 31, 2018, were reviewed. This study was approved by the Ethical Committee. Data collected included patient demographics and operative details such as the extent of thyroidectomy and the extent of LND.

Surgery: A total thyroidectomy was performed if contralateral thyroid nodules, extra-thyroid extension, cervical lymph node involvement, and a firstdegree family history of thyroid carcinoma. A less-than-total thyroidectomy (Near-total (Figure 1(a)), Subtotal or Lobectomy) was selected for patients with small, isolated, intrathyroidal carcinomas without gross nodal involvement.

Extent of neck dissection includes berry picking was to remove only suspicious and enlarged lymph nodes, central neck compartment (level VI) (Figure 1(b)) which are bordered by the hyoid bone superiorly, suprasternal notch inferiorly, and the carotid sheaths laterally include pretracheal and paratracheal nodes, the precricoid (Delphian) nodes, and the perithyroidal nodes. Central compartment node dissection (CCND) is usually performed with thyroidectomy for prophylactic purposes, whereas lateral neck dissection is performed only in patients in whom metastasis is clinically evident. Modified radical neck dissection (ipsilateral neck dissection, bilateral a modified radical neck dissection type 3, (Figure 1(c)) Its superior border is the skull base and mandible, the inferior border is the subclavian vein, the lateral border is posterior margin of sternocleidomastoid muscle, Neck dissection spares the internal jugular vein, spinal 

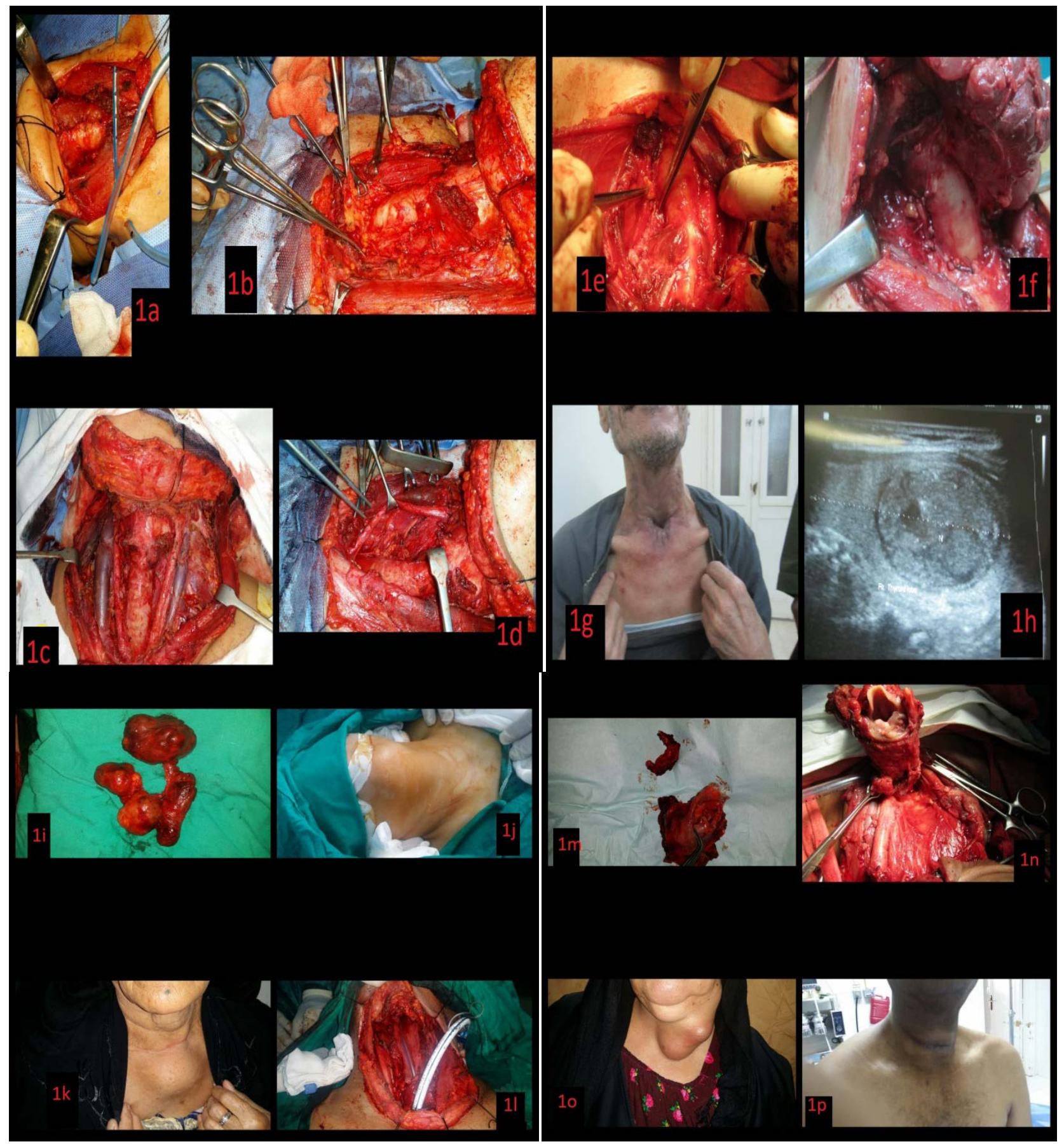

Figure 1. (a-p) Operative technique and pictures of some operated cases.

accessory nerve, and the sternocleidomastoid muscle unless they were involved by disease.

Recurrent laryngeal nerves were routinely identified (Non Recurrent RLN (Figure 1(d)) and exposed up until their insertion in the larynx, and parathyroid glands were preserved in situ as far as possible following the capsular principle of dissection, (Figure 1(e), Figure 1(f)). At the time of surgery, if any portion of the parathyroid gland is identified to be devascularized, it should be auto-trans- 
planted, preferably in the sternomastoid muscle or in the strap muscles.

Post-operative complications: Postoperative complications including hypoparathyroidism, recurrent laryngeal nerve (RLN) injury or palsy, bleeding/ hematoma, seroma, chyle fistula, shoulder dysfunction due to sacrifice of the accessory nerve. Hypoparathyroidism is defined by low levels of calcium in the blood $(<2.0 \mathrm{mmol} / \mathrm{L})$ and/or low levels of PTH $(<15 \mathrm{pg} / \mathrm{mL})$. Hypoparathyroidism and recurrent laryngeal nerve palsy were classified as transient or permanent based on 6 months after surgery [6]. True bilateral vocal cord paralysis may require tracheostomy to secure the airway (Figure $1(\mathrm{~g})$ ).

Surveillance and follow-up: The patients were followed up every 3 to 6 months for 5 years and annually thereafter, if exhibiting no evidence of disease. These visits included physical examination, neck US (Figure $1(\mathrm{~h})$ ), chest radiography, whole-body iodine scanning and measurement of serum-free thyroxine, thyrotropin, thyroglobulin $(\mathrm{Tg})$ and anti-thyrogobulin antibody concentrations.

Radioactive iodine therapy: Apart from lymph node involvement, indications for postoperative 131I treatment were a tumor $>1 \mathrm{~cm}$, extracapsular thyroid invasion (Figure 1(i)) or locoregional extension, unfavorable histological subtype (follicular, diffuse sclerosing, or tall cell-variant papillary cancer), multifocal disease, patients received $30-100 \mathrm{mCi}$ of radioactive iodine therapy $2-3$ months after surgery.

Statistical methods: SPSS version 25.0 was used in data management. Mean and standard deviation or median and range were used for numerical data description. Chi-square test and Fisher exact tests were used for testing proportion independence. Overall survival was defined from date of diagnosis to date of death and locoregional control was defined from date of surgery to date of local recurrence. Kaplan Meier method estimated survival and log rank test compared curves. $\mathrm{P}$ value was always two tailed and significant at 0.05 level.

\section{Results}

The median duration of follow-up was 43.50 months. The majority of patients were female (56.6\%) and the mean age was 42.73 years. pathology was classic papillary thyroid cancer in (81.6\%) patients and included variants such as follicular (3.1\%), tall cell (8.2\%), columnar (2.0\%), solid (1.5\%) and sclerosing (3.6\%). On pathology review, the Median tumor size was $21.00 \mathrm{~mm}, 44.4 \%$ had multi-focal disease, $34.2 \%$ had extra-capsular invasions, $31.6 \%$ had extra-thyroidal extension, and $21.4 \%$ reported lymphovascular invasion., $79.0 \%$ of them went on to receive radioactive iodine treatment after the initial surgery (Table 1).

Extent of surgery and neck dissection: Total thyroidectomy was done in $68.9 \%$, while near-total thyroidectomy in $5.1 \%$, subtotal thyroidectomy in $4.1 \%$, thyroid lobectomy in $3.1 \%$ and completion thyroidectomy in $18.9 \%$.

Regarding extent of LND: No Lymph nodes Dissection in 10.7\%, Berry Picking in $6.1 \%$, central compartment neck dissection in $41.8 \%$, central compartment 
Table 1. Demographics and characteristics of initial surgery.

\begin{tabular}{|c|c|c|c|}
\hline & & $\mathrm{n}$ & $\%$ \\
\hline & No & 109 & $55.6 \%$ \\
\hline \multirow[t]{3}{*}{ Multifocality } & Yes & 87 & $44.4 \%$ \\
\hline & Total & 196 & $100.0 \%$ \\
\hline & No & 129 & $65.8 \%$ \\
\hline \multirow[t]{3}{*}{ Capsular invasion } & Yes & 67 & $34.2 \%$ \\
\hline & Total & 196 & $100.0 \%$ \\
\hline & No & 134 & $68.4 \%$ \\
\hline \multirow[t]{5}{*}{ Extra-thyroidal extension } & Yes & 62 & $31.6 \%$ \\
\hline & Total & 196 & $100.0 \%$ \\
\hline & Classic papillary & 160 & $81.6 \%$ \\
\hline & Columnar & 4 & $2.0 \%$ \\
\hline & Follicular & 6 & $3.1 \%$ \\
\hline \multirow[t]{5}{*}{$\begin{array}{l}\text { Variant of papillary } \\
\text { thyroid carcinoma }\end{array}$} & Sclerosing & 7 & $3.6 \%$ \\
\hline & Solid & 3 & $1.5 \%$ \\
\hline & Tall & 16 & $8.2 \%$ \\
\hline & Total & 196 & $100.0 \%$ \\
\hline & No & 154 & $78.6 \%$ \\
\hline \multirow[t]{2}{*}{ Lymphovascular invasion } & Yes & 42 & $21.4 \%$ \\
\hline & Total & 196 & $100.0 \%$ \\
\hline
\end{tabular}

neck dissection with modified ipsilateral radical neck dissection in $12.2 \%$, central compartment neck dissection with modified bilateral radical neck dissection in $26.0 \%$, central compartment dissection with both modified bilateral radical neck dissection and superior mediastinal lymph node dissection 3.1\% (Table 2).

Local recurrences occurred in $6.1 \%$ of patients (Figure 1(j) \& Figure 1(k)). Surgery for advanced thyroid malignancy include partial laryngectomy in $1.02 \%$, total laryngectomy in $1.02 \%$, (Figure $1(1)$, Figure $1(\mathrm{~m})$ ) pharyngolaryngectomy in $1.02 \%$, (Figure $1(\mathrm{n})$ ) tracheal resection in $1.53 \%$ and tracheostomy in $5.7 \%$ which is permanent in $2.6 \%$ and temporary in $3.1 \%$ (Table 3 ).

Extent of thyroid surgery and RLN palsy: No RLN affection with thyroid lobectomy/subtotal thyroidectomy and only $10 \%$ of temporary with near-total thyroidectomy while total thyroidectomy had $0.7 \%$ permanent and $8.1 \%$ temporary affection which increased in completion thyroidectomy to $2.7 \%$ as permanent and $16.2 \%$ as temporary ( $\mathrm{P}$ value $=0.538$ ) (Figure 2 ).

Extent of lymph node dissection and RLN palsy: No incidence of RLN palsy in Berry picking while temporary in central compartment neck dissection, central compartment neck dissection + modified ipsilateral radical neck dissection, central compartment neck dissection + modified bilateral radical neck dissection and central compartment dissection + modified bilateral radical neck dissection + 
superior mediastinal lymph node dissection $(7.3 \%, 12.5 \%, 15.7 \%$ and $16.7 \%$, respectively) and permanent palsy only in 3.9\% (one malignant invasion (Figure $1(\mathrm{p})$ ) of patient central compartment neck dissection. + modified Bilateral radical neck dissection) (Figure 3).

Table 2. Extent of surgery and neck dissection.

\begin{tabular}{|c|c|c|c|}
\hline & & $\mathrm{n}$ & $\%$ \\
\hline \multirow{4}{*}{ RAI ablation } & No & 100 & $51.0 \%$ \\
\hline & Yes & 96 & $49.0 \%$ \\
\hline & Total & 196 & $100.0 \%$ \\
\hline & Completion thyroidectomy & 37 & $18.9 \%$ \\
\hline \multirow{4}{*}{$\begin{array}{l}\text { The extent of } \\
\text { thyroid surgery }\end{array}$} & Thyroid lobectomy & 6 & $3.1 \%$ \\
\hline & Near-total Thyroidectomy & 10 & $5.1 \%$ \\
\hline & Subtotal thyroidectomy & 8 & $4.1 \%$ \\
\hline & Total thyroidectomy & 135 & $68.9 \%$ \\
\hline \multirow{8}{*}{$\begin{array}{l}\text { Extent of lymph } \\
\text { nodes dissection }\end{array}$} & Total & 196 & $100.0 \%$ \\
\hline & No lymph nodes dissection & 21 & $10.7 \%$ \\
\hline & Berry picking lymph nodes dissection & 12 & $6.1 \%$ \\
\hline & Central compartment neck dissection & 82 & $41.8 \%$ \\
\hline & $\begin{array}{c}\text { Central compartment neck dissection, }+ \text { modified } \\
\text { ipsilateral radical neck dissection }\end{array}$ & 24 & $12.2 \%$ \\
\hline & $\begin{array}{l}\text { Central compartment neck dissection. + modified } \\
\text { bilateral radical neck dissection }\end{array}$ & 51 & $26.0 \%$ \\
\hline & $\begin{array}{l}\text { Central compartment dissection }+ \text { modified bilateral } \\
\text { radical neck dissection }+ \text { superior mediastinal lymph } \\
\text { node dissection }\end{array}$ & 6 & $3.1 \%$ \\
\hline & Total & 196 & $100.0 \%$ \\
\hline
\end{tabular}

Table 3. Recurrence rate and treatment of advanced malignancy.

\begin{tabular}{|c|c|c|c|}
\hline & & $\mathrm{n}$ & $\%$ \\
\hline \multirow{3}{*}{ Local recurrence } & No & 184 & $93.9 \%$ \\
\hline & Yes & 12 & $6.1 \%$ \\
\hline & Total & 196 & $100.0 \%$ \\
\hline \multirow{5}{*}{$\begin{array}{l}\text { Surgery for advanced thyroid } \\
\text { malignancy }\end{array}$} & Partial laryngectomy & 2 & $22.2 \%$ \\
\hline & Pharyngolaryngectomy & 2 & $22.2 \%$ \\
\hline & Total laryngectomy & 2 & $22.2 \%$ \\
\hline & Tracheal resection & 3 & $33.3 \%$ \\
\hline & Total & 9 & $100.0 \%$ \\
\hline \multirow{4}{*}{ Tracheostomy } & No & 185 & $94.4 \%$ \\
\hline & Permanent & 5 & $2.6 \%$ \\
\hline & Temporary & 6 & $3.1 \%$ \\
\hline & Total & 196 & $100.0 \%$ \\
\hline
\end{tabular}




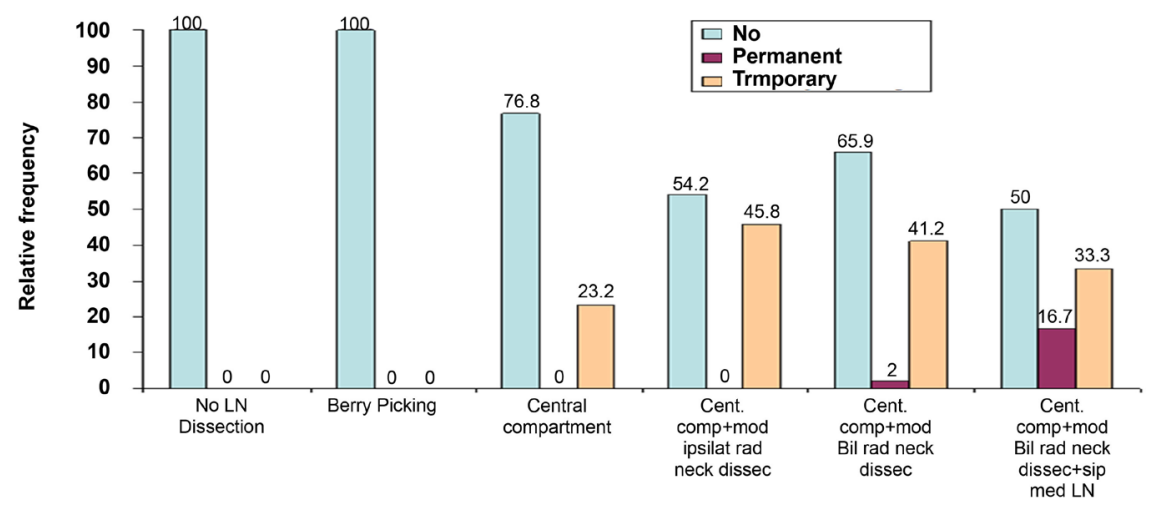

Figure 2. Recurrent laryngeal nerve palsy as related to extent of thyroid surgery in thyroid cancer patients.

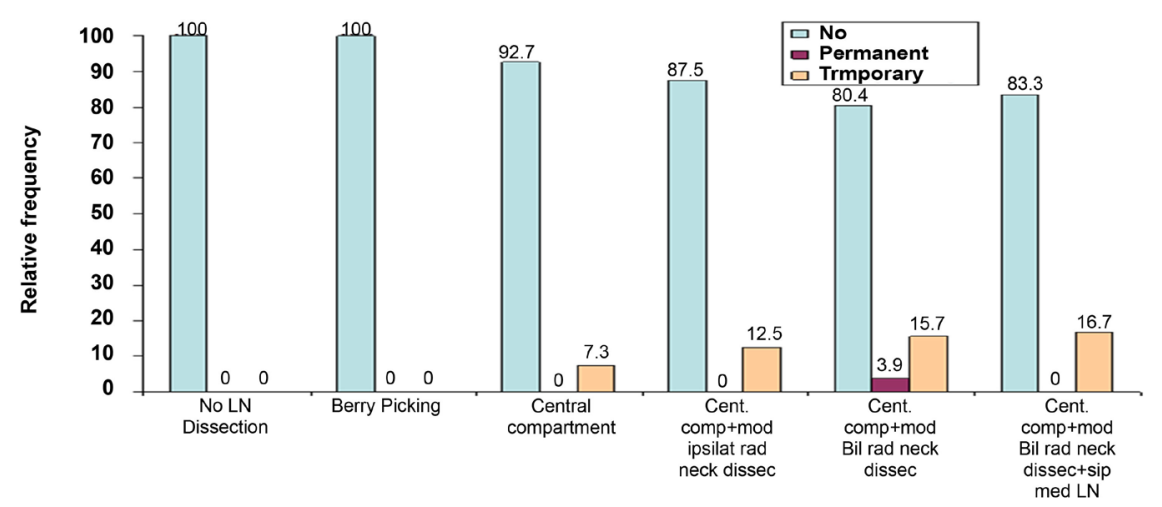

Figure 3. Recurrent laryngeal nerve palsy as related to type of lymph node dissection in thyroid cancer patients.

Extent of thyroid surgery and Hypoparathyroidism: No parathyroid affection in thyroid lobectomy, subtotal or near total thyroidectomy whereas, total thyroidectomy associated with temporary hypoparathyroidism in $25.9 \%$ of cases and completion thyroidectomy was associated with temporary hypoparathyroidism in $48.6 \%$ and permanent hypoparathyroidism in $5.4 \%$. Completion thyroidectomy has significantly higher temporary hypoparathyroidism (but not permanent) than other types of surgeries $(\mathrm{P}<0.001)$ (Figure 4).

Extent Of Lymph Nodes Dissection and Hypoparathyroidism: No parathyroid affection in Berry picking while central compartment neck dissection was associated with $23.2 \%$ temporary hypoparathyroidism, central compartment neck dissection + modified Ipsilateral radical neck dissection with $45.8 \%$ temporary hypoparathyroidism, central compartment neck dissection + modified bilateral radical neck dissection with $41.2 \%$ temporary hypoparathyroidism and $2.0 \%$ permanent hypoparathyroidism and central compartment dissection+ modified bilateral radical neck dissection + superior mediastinal lymph node dissection with $33.3 \%$ temporary hypoparathyroidism, $16.7 \%$ permanent hypoparathyroidism central compartment neck dissection. + modified bilateral radical neck dissection has significantly higher temporary hypoparathyroidism as compared to other node dissection modalities $(\mathrm{P}<0.001)$ (Figure 5$)$. 


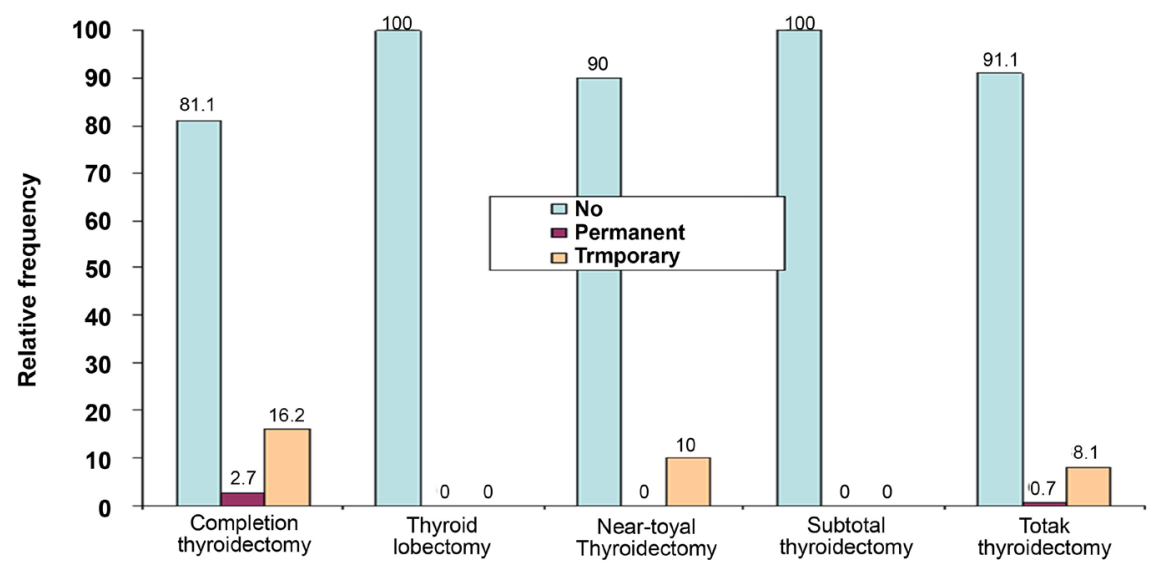

Figure 4. Hypoparathyroidism related to extent of thyroid surgery in thyroid cancer patients.

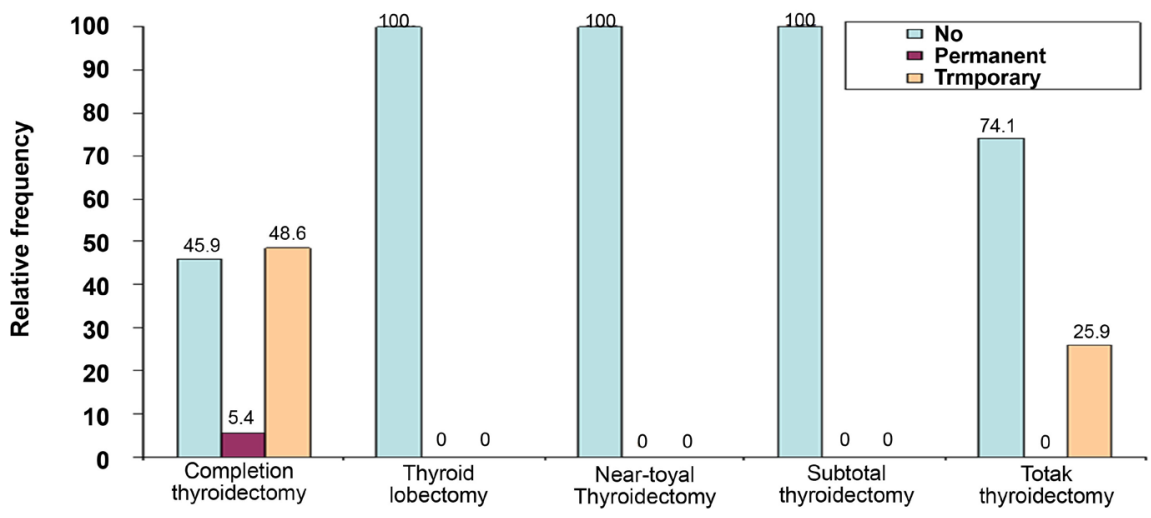

Figure 5. Hypoparathyroidism as related to type of lymph node dissection in thyroid cancer patients.

By contrast, the incidence of hematoma, which was $1.5 \%$ overall, was not associated with the extent of surgery $(\mathrm{P}=0.464)$. Seroma was reported in $7.1 \%$ of all patients, Chyle fistula in $2.6 \%$, after lateral neck dissection, accessory nerve weakness leading to shoulder disability in $2 \%$ temporary in $1.5 \%$, permanent in $0.5 \%$ and wound infection occurred in $1.5 \%$. No perioperative mortality was observed.

\section{Discussion}

The rationale of total thyroidectomy is based on several factors including: 1) the high frequency of multifocal disease; 2) the facilitation of RAI ablation of remaining thyroid tissue; 3) the opportunity to follow patients with thyroglobulin levels and 131I scans; and 4) the avoidance of reoperative neck surgery, at low-volume centers may choose to offer a unilateral operation (i.e., lobectomy), near-total or total and subtotal thyroidectomy. Completion thyroidectomy allows for better postoperative monitoring and even makes adjuvant $\mathrm{I}^{131}$ unnecessary. The risk of recurrence in the contralateral lobe is $5 \%-24 \%$ [7].

In our study, total thyroidectomy in $87.8 \%(18.9 \%)$ of them are completion 
thyroidectomy, $68.9 \%$ in primary procedures, less than total thyroidectomy in $12.2 \%$ (near-total thyroidectomy in $5.1 \%$, subtotal thyroidectomy in $4.1 \%$, thyroid lobectomy in 3\%).

The risk of temporary/permanent vocal palsy increased to $12.9 \% / 9.7 \%$ in those who had undergone less than total lobectomy in the previous surgery. Permanent vocal palsy was reported in $14 \%$ of the reoperation patients [8]. Damage of recurrent laryngeal nerve can reach 20\% (ranging from $0.7 \%$ to $4.5 \%$ during the first operation), and while recurrent laryngeal nerve injury has been observed with an incidence of $1 \%-3 \%$ [9].

In our series, the rate of transient/permanent RLN palsy increased with completion thyroidectomy, No RLN affection with lobectomy and subtotal thyroidectomy and only $10 \%$ of temporary of near-total thyroidectomy while total thyroidectomy had $0.7 \%$ permanent and $8.1 \%$ temporary increased in completion thyroidectomy to $2.7 \%$ in permanent, $16.2 \%$ in temporary $(\mathrm{P}$ value $=0.538)$.

Hypoparathyroidism is the most frequent complication after thyroidectomy due to the incidental removal of parathyroid glands or poor blood flow to the glands [4]. The incidence rates of transient and permanent hypoparathyroidism increased significantly with increasing extent of surgery mostly due to more ischemic changes to parathyroids. Thus, hypoparathyroidism following thyroid surgery is likely to be due to the drop of blood flow to the parathyroid glands with increasing extent of surgery [4]. The risk of hypoparathyroidism can reach $30 \%$ ( $8 \%$ to $13 \%$ ) in primary procedures [10]. Transient hypocalcaemia has been reported with an incidence of up to $30 \%$ [9], rates of hypoparathyroidism (transient, $31.8 \%$; permanent, $3.6 \%$ ) with preservation of blood supply to the parathyroid glands [11]. Re-thyroidectomies associated with a higher risk of postoperative complications [11]. Revision surgery of the central compartment places the parathyroid glands at an increased risk of devascularization or inadvertent removal [9]. In our institution, we found that, no hypoparathyroidism in Less than total thyroidectomy, total thyroidectomy associated with temporary hypoparathyroidism occur in $25.9 \%$ and completion thyroidectomy associated with temporary hypoparathyroidism in $48.6 \%$, permanent hypoparathyroidism in $5.4 \%$. Completion thyroidectomy has significantly higher temporary hypoparathyroidism (but not permanent) than other types of surgeries $(\mathrm{P}<0.001)$.

Transient hypoparathyroidism is the main complication of CLND. The incidence of transient hypoparathyroidism was reported $40.6 \%$ to $42.8 \%$, and $2.4 \%$ patients had permanent hypoparathyroidism. Moreover, it was reported that $10.8 \%$ patients had hypocalcaemia that required calcium supplementation. Another study indicated only $1.6 \%$ patients had permanent hypoparathyroidism [12]. In the present study, the incidence of temporary hypoparathyroidism range from $23.2 \%$ to $45.8 \%$. The main cause of temporary hypoparathyroidism may be devascularization of parathyroid glands during dissection. Central compartment neck dissection + modified bilateral radical neck dissection has significantly higher temporary hypoparathyroidism as compared to other node dissection modalities $(\mathrm{P}<0.001)$. 
Temporary RLN injury is another important complication of CLND and transient RLN palsy was found in 7.4\% patients who all recovered within 3 months after initial surgery. Permanent RLN palsy also found $1.0 \%$ to $7.0 \%$ in some studies, but all recovered within 6 months postoperatively [12]. The RLN is more vulnerable to damage during secondary thyroidectomy [8]. In the present study, the incidence of temporary RLN injury range from $7.3 \%$, to $16.7 \%$, all recovered within 6 months postoperatively while permanent only in 3.9\%. These results indicate that dissection can be safely implemented during CLND.

Complications after thyroidectomy when compared with thyroidectomy and CLND, CLND didn't increase the incidence of recurrent laryngeal nerve injury. It was reported that $1 \%-2 \%$ only of patients who underwent total thyroidectomy experienced permanent hypocalcaemia or permanent RLN injury, and the rate of complications was not increased with the addition of CLND [13].

In this study, 3.9\% of patients had permanent recurrent laryngeal nerve injury, and another $5.4 \%$ of patients experienced permanent hypocalcaemia. The rate of transient RLN palsy increased significantly with increasing extent of surgery, whereas permanent RLN palsy was not related to the extent of surgery; this is likely that permanent palsy was caused by invasion of the RLN nerve or accidental injuries.

Radical operations, such as those with increased extent of LND, may lead to clinically important postoperative morbidities shoulder dysfunctions were temporary in duration, and only 1 patient had long-term shoulder dysfunction [14] [15]. In our study, accessory nerve weakness leading to shoulder disability occurred in $2 \%$; temporary in $1.5 \%$ and permanent in $0.5 \%$.

Resection of critical structures such as, trachea, and esophagus can be associated with significant morbidity; the most commonly involved structures included trachea (37\%), esophagus (21\%), and larynx (12\%) [4]. Laryngeal and esophageal invasion was observed by Clayman et al. [13]. In our group total laryngectomy in $1.02 \%$, due to extensive laryngeal infiltration and $1.02 \%$, underwent partial laryngectomy, pharyngolaryngectomy in $1.02 \%$, tracheal resection in $1.53 \%$ and tracheostomy in $5.7 \%$ which is permanent in $2.6 \%$ and temporary in $3.1 \%$.

The rate of chyle fistula is dependent on the extent of surgical procedure in the neck. The reported incidence of chylothorax after thyroidectomy with lateral ND ranges from $1.2 \%$ to $3.8 \%$ [16]. In our study, Chyle fistula had an overall incidence of $2.6 \%$. Tumor size, which was larger than $5 \mathrm{~mm}$, had a stronger relationship with CLNM compared with less than $5 \mathrm{~mm}$. observed that PTMC with tumor size $>7 \mathrm{~mm}$ was frequently associated with poor prognosis [17]. In this study, the Median tumor size was $21.00 \mathrm{~mm}$. Capsular invasion is traditionally thought to be predictive for CLNM18. In this research, Capsular invasion was not rare (13.7\%), which is consistent with the rate reported by previous studies (9.9\% - 26.8\%) [17]. In our study, $34.2 \%$ had extra-capsular invasions. Multifocality occurred in $40.7 \%$ of 273 PTMCs, and $62.5 \%$ of them had CLNM, which was similar to other studies. Multifocality has been reported in $18 \%$ to $87 \%$ of 
patients with PTC [17]. In present study, 44.4\% had multi-focal disease. Local recurrences are found in 5\% - 20\% of patients with PTC, two thirds of which are localized to cervical lymph nodes [18]. In our study, local recurrences occurred in $6.1 \%$.

\section{Conclusion}

Thyroid cancer surgeries with neck dissection are safe but associated with transient complications, such as transient RLN injury, transient hypocalcaemia whereas; the incidence of permanent complications is very low and not significantly different from that for total thyroidectomy alone. Therefore, an understanding of the relationship between complication patterns and the extent of surgery seems to be crucial for thyroid cancer surgery. Balancing surgical morbidity and long-term benefits, as well as better patient selection, are the keys.

\section{Conflicts of Interest}

The authors declare no conflicts of interest regarding the publication of this paper.

\section{References}

[1] Adam, M.A., Pura, J., Gu, L., Dinan, M.A., Tyler, D.S., Reed, S.D., Scheri, R., Roman, S.A. and Sosa, J.A. (2014) Extent of Surgery for Papillary Thyroid Cancer Is Not Associated with Survival: An Analysis of 61,775 Patients. Annals of Surgery, 260, 605-607. https://doi.org/10.1097/SLA.0000000000000925

[2] Yoo, H.S., Shin, M.C., Ji, Y.B., Song, C.M., Lee, S.H. and Tae, K. (2018) Optimal Extent of Prophylactic Central Neck Dissection for Papillary Thyroid Carcinoma: Comparison of Unilateral versus Bilateral Central Neck Dissection. Asian Journal of Surgery, 41, 363-369. https://doi.org/10.1016/j.asjsur.2017.03.002

[3] Keum, H.S., Ji, Y.B., Kim, J.M., Jeong, J.H., Choi, W.H., Ahn, Y.H. and Tae, K. (2012) Optimal Surgical Extent of Lateral and Central Neck Dissection for Papillary Thyroid Carcinoma Located in One Lobe with Clinical Lateral Lymph Node Metastasis. World Journal of Surgical Oncology, 10, 221. https://doi.org/10.1186/1477-7819-10-221

[4] Lee, Y.S., Nam, K.H., Chung, W.Y., Chang, H.S. and Park, C.S. (2010) Postoperative Complications of Thyroid Cancer in a Single Center Experience. Journal of Korean Medical Science, 25, 541-545. https://doi.org/10.3346/jkms.2010.25.4.541

[5] Shaha, A.R. (2017) Lobectomy vs Total Thyroidectomy-Have We Resolved the Debate? International Journal of Surgery, 38, 141-142.

https://doi.org/10.1016/j.ijsu.2016.12.011

[6] Bilezikian, J.P., Khan, A., Potts, J.T., Brandi, M.L., Clarke, B.L., Shoback, D., Jüppner, H., D’Amour, P., Fox, J., Rejnmark, L., Mosekilde, L., Rubin, M.R., Dempster, D., Gafni, R., Collins, M.T., Sliney, J. and Sanders, J. (2011) Hypoparathyroidism in the Adult: Epidemiology, Diagnosis, Pathophysiology, Target-Organ Involvement, Treatment, and Challenges for Future Research. Journal of Bone and Mineral Research: The Official Journal of the American Society for Bone and Mineral Research, 26, 2317-2337. https://doi.org/10.1002/jbmr.483

[7] Proczko, M., Stefaniak, T., Sworczak, K., Kobiela, J., Lachinski, A.J., Stepaniak, P. and Sledzinski, Z. (2013) Completion Thyroidectomy of Well-Differentiated Thy- 
roid Cancer-A Prospective, Randomised Study. Endokrynologia Polska, 64, 335-339. https://doi.org/10.5603/EP.2013.0014

[8] Chiang, F.Y., Lee, K.W., Huang, Y.F., Wang, L.F. and Kuo, W.R. (2004) Risk of Vocal Palsy after Thyroidecitomy with Identification of the Recurrent Laryngeal Nerve. The Kaohsiung Journal of Medical Sciences, 20, 431-436. https://doi.org/10.1016/S1607-551X(09)70181-0

[9] Soprani, F., Bondi, F., Puccetti, M. and Armaroli, V. (2012) Charcoal Tattoo Localization for Differentiated Thyroid Cancer Recurrence in the Central Compartment of the Neck. Acta Otorhinolaryngologica Italica, 32, 87-92.

[10] Giugliano, G., Proh, M., Gibelli, B., Grosso, E., Tagliabue, M., De Fiori, E., Maffini, F., Chiesa, F. and Ansarin, M. (2014) Central Neck Dissection in Differentiated Thyroid Cancer: Technical Notes. Acta Otorhinolaryngologica Italica, 34, 9-14.

[11] Woo, J.H., Park, K.N., Lee, J.Y. and Lee, S.W. (2016) Predictive Factors of Superior Mediastinal Nodal Metastasis from Papillary Thyroid Carcinoma-A Prospective Observational Study. PLoS ONE, 11, e0148420. https://doi.org/10.1371/journal.pone.0148420

[12] Stack, B.C., Ferris, R.L., Goldenberg, D., Haymart, M., Shaha, A., Sheth, S., Sosa, J.A. and Tufano, R.P. (2012) American Thyroid Association Consensus Review and Statement Regarding the Anatomy, Terminology, and Rationale for Lateral Neck Dissection in Differentiated Thyroid Cancer. Thyroid, 22, 501-508. https://doi.org/10.1089/thy.2011.0312

[13] Price, D.L., Wong, R.J. and Randolph G.W. (2008) Invasive Thyroid Cancer: Management of the Trachea and Esophagus. Otolaryngologic Clinics of North America, 41, 1155-1168. https://doi.org/10.1016/j.otc.2008.08.002

[14] McNamara, W.F., Wang, L.Y., Palmer, F.L., Nixon, I.J., Shah, J.P., Patel, S.G. and Ganly, I. (2016) Pattern of Neck Recurrence after Lateral Neck Dissection for Cervical Metastases in Papillary Thyroid Cancer. Surgery, 159, 1565-1571. https://doi.org/10.1016/j.surg.2016.02.005

[15] Yang, J., Gong, Y., Yan, S., Zhu, J., Li, Z. and Gong, R. (2016) Risk Factors for Level V Lymph Node Metastases in Solitary Papillary Thyroid Carcinoma with Clinically Lateral Lymph Node Metastases. Cancer Medicine, 5, 2161-2168. https://doi.org/10.1002/cam4.792

[16] Merki, V., Pichler, J., Giger, R. and Mantokoudis, G. (2016) Chylothorax in Thyroid Surgery: A Very Rare Case and Systematic Review of the Literature. Journal of Otolaryngology-Head \& Neck Surgery, 45, 52. https://doi.org/10.1186/s40463-016-0166-y

[17] Li, M., Zhu, X.Y., Lv, J., Lu, K., Shen, M.P., Xu, Z.L. and Wu, Z.S. (2017) Risk Factors for Predicting Central Lymph Node Metastasis in Papillary Thyroid Microcarcinoma (CN0): A Study of 273 Resections. European Review for Medical and Pharmacological Sciences, 21, 3801-3807.

[18] Nixon, I.J., Wang, L.Y., Ganly, I., Patel, S.G., Morris, L.G., Migliacci, J.C., Tuttle, R.M., Shah, J.P. and Shaha, A.R. (2016) Outcomes for Patients with Papillary Thyroid Cancer Who Do Not Undergo Prophylactic Central Neck Dissection. British Journal of Surgery, 103, 218-225. https://doi.org/10.1002/bjs.10036 